\title{
Optimization Method of the Car Seat Rail Abnormal Noise Problem Based on the Finite Element Method
}

\author{
Huijie Yu, Xinkan Zhang, and Chen Zhang \\ School of Mechanical Engineering, University of Shanghai for Science and Technology, Shanghai, China \\ Correspondence should be addressed to Huijie Yu; yuhj2000@163.com
}

Received 1 April 2017; Revised 31 May 2017; Accepted 18 July 2017; Published 7 September 2017

Academic Editor: Michele Palermo

Copyright (C) 2017 Huijie Yu et al. This is an open access article distributed under the Creative Commons Attribution License, which permits unrestricted use, distribution, and reproduction in any medium, provided the original work is properly cited.

The finite element model of the seat rail is established with a spring-damping element to simulate the ball in the rail joint part. The stiffness and damping parameters of the joint part are determined by the combination of finite element method and experiment. Firstly, the natural frequencies and modes of the guide rail are obtained by modal experiment. The stiffness of the spring-damping element is optimized in the finite element software to make the natural frequencies and modes of the system consistent with the experimental ones. Secondly, the dynamic response curve of the key nodes is obtained through sweeping experiment, and the damping of the spring-damping element is optimized in the finite element software to make the nodal response of the system output consistent with the experiment. Then, the gap of the joint part of the car seat rail is studied considering the factors of load and structure randomness. The influence factors of the gap are selected by Hammersley experimental design method. The results show that the gap is normally distributed, and therefore the confidence interval of the gap is obtained. Finally, the joint probability distribution of the gap is obtained under the condition that the load and the structure are all random, which provides the theoretical guidance for determining the reasonable gap of the joint.

\section{Introduction}

With the progress of the times and the improvement of living standards, private cars have been rapidly entering thousands of households. The users' requirements for private cars have also changed from a simple trip to a comfortable ride. Some of the advanced foreign car manufacturers in the early 1980s began to pay attention to body structure vibration and rough road bumps producing noise problems. In the 1990s, Volkswagen, GM, Ford, Toyota, and other well-known car companies set up research centers to deal with the noise problems from vehicle structural vibration, noise, and rough road surface roughness [1]. Nowadays, the rising awareness on environment issues keeps stimulating higher demand for vehicles' qualities. Therefore, the international automotive industry has put forward a new standard, namely, Noise, Vibration, and Harshness standard, referred to by NVH standard [2]. In general, all tactile and auditory perceptions of the occupants in the car belong to the NVH problem. The more serious the car's vibration and noise problems are, the more irritable and uneasy the occupant will become.
From the NVH point of view, a vehicle is a system consisting of an exciter (engine), an actuator (suspension, etc.), and a vibration noise generator (body). Today, NVH problem is one of the major problems that car manufacturers have been most concerned about, from large system-level vehicle $\mathrm{NVH}$ standard analysis process to small NVH componentlevel problems. According to statistics, most of the major car manufacturers have put more than $20 \%$ of the R\&D funding to solve the vehicle NVH problem [3].

The guide rail of car seat is the connection between the car seat and the car floor. Its role is to adjust the seat position back and forth and to protect the occupants' safety. Seat rail quality determines the user experience. A good rail should not only be safe and reliable in the locked state, but also be smooth in the adjustment of seat position forth and back. However, when the vehicle is moving, the car seat rails will produce abnormal sound, which is usually solved by workers with their own experience when they encounter the problems. Their temporary solutions are inadequate to solve the seat rail abnormal sound completely. However, the increasing complaint and discontent of the users have 


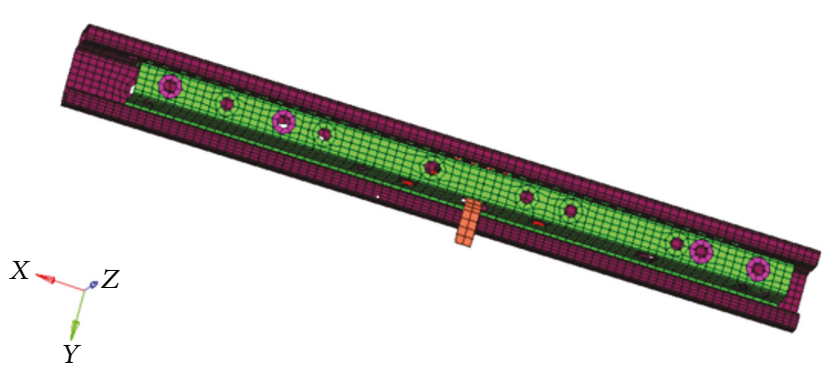

(a) Finite element model of seat rail

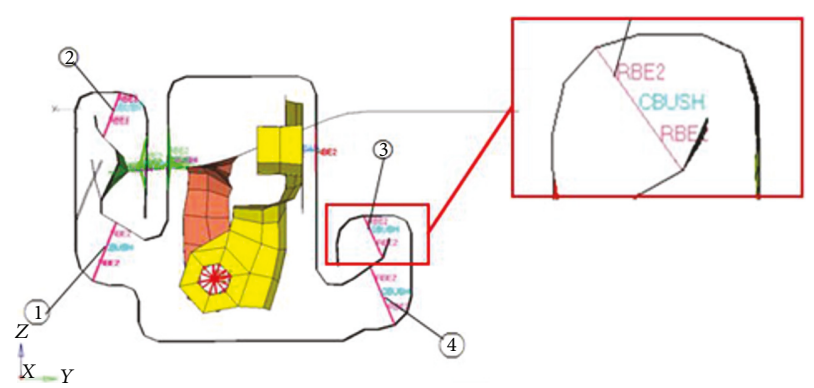

(b) Schematic diagram of steel ball position

Figure 1

caught seat manufacturers' attention. The manufacturers have been putting great efforts to conduct experimental research to explore the causes of this problem. After long trials and exploration, engineers attribute the abnormal sound of rails to the uneven internal force of the balls. There are 4 slides between the inner rail and the outer rail, and 4 to 6 balls inside each slide. When the guide rail receives the random road excitation from the vehicle body, balls are subjected to uneven force. Some of them show the state of compression, and some of them show the state of separation. When the rail is subjected to the load of driving direction, noise is generated when the inner and outer rails are misaligned. Of course, the field engineer also gives the solution to this problem, which is to preload the rail before mounting. For example, if the nominal diameter of the steel ball is $6 \mathrm{~mm}$, the actual spacing between the inner and outer rails is preloaded to $5.8 \mathrm{~mm}$ during installation so that the ball is actually in a preload state after the installation is complete. This solution is effective in the actual operation process. If the preload value is reasonable, the problem of abnormal sound in rails will be improved significantly. Therefore, the preload value for guidance is the key to solve the problem. If the preload is too little, noise will not be reduced effectively. On the other hand, if the preload is too large, serious slip will lock in the rail. Thus, the preload value, which is set to be the maximum value of the gap, may suppress the occurrence of the gap effectively, and it will be a reasonable preload value.

With the development of finite element method, it is an effective tool to solve the vibration and noise problem of vehicle seat by using finite element technology to simulate the dynamic characteristics of various parts of seat. To solve these problems, the dynamic finite element software can be used to analyze the dynamics of the steel ball. The gap between the steel ball and the inner and outer rails is analyzed by statistic method to observe the distribution of the gap and give the reasonable preloading value for guidance. However, many of the problems encountered will be the key to the successful solution. First of all, the interface between the steel ball and the inner and outer rail is actually a linear roller guide model. How can we establish the finite element model of the ball, so that the combination can be simulated exactly? It is also necessary to find a definite amount that can characterize the compacted and segregated state that occurs between the joint part. Secondly, this gap is affected by a number of uncertain factors, like random excitation of road, manufacturing error of balls, elastic modulus, and so on. However, deterministic finite element dynamic analysis will not show the influence factors other than external excitation, which cannot meet the actual demand of this issue. The stochastic finite element theory can treat the load, the strength of materials, and parts of the geometry as random variables to solve the problem. It is the numerical analysis theory based on the traditional finite element theory, and it is the combination of random field theory and finite element method [4].

In this paper, a finite element modeling method is studied for a vehicle seat rail. The spring-damping modeling method for the joint part of linear roller is studied emphatically, and a complete method is proposed to optimize the stiffness and damping parameters of the joint using a combination of experiment and finite element analysis. Then, a series of dynamic analyses are carried out on the new dynamic model, and the distribution of the joint gap under the dynamic excitation is statistically analyzed. Finally, the distribution of the joint gap is investigated by using DOE and stochastic study considering the external excitation and the uncertainty of the structure itself.

\section{FEA Model Set-Up}

As the thicknesses of the inner and outer guide rails are all $1.4 \mathrm{~mm}$, the rails can be regarded as thin-walled parts. We adopt the method of extracting the middle layer. Using the CAE software, thin-walled parts are mathematically discretized by shell element, and a detailed finite element model is established. In this model, the outer rail is $450 \mathrm{~mm}$ long and the inner rail is $402 \mathrm{~mm}$. The CQUAD4 unit with the basic dimension of $5 \mathrm{~mm} \times 5 \mathrm{~mm}$ is used. There are 7913 nodes and 7406 units in total. The isotropic material is used to establish the material model. Its elastic modulus $E$ is $210 \mathrm{GPa}$. Poisson's ratio is 0.3 . Density is $7900 \mathrm{Kg} / \mathrm{m}^{3}$. The finite element model is shown in Figure 1.

The handling of the internal steel ball is the key to this modeling. There are twenty guide balls in the rail, eight of which are $\Phi 6$, and twelve of which are $\Phi 8$. According to their position in the guide rail structure, the steel balls are divided into four groups, as shown in Figure 1.

Figure 1 shows the finite element model of the guide rail and the position diagram of the inner ball. In the modeling 
process, steel balls are represented by CBUSH spring elements overlapped with each other in the position of the steel ball. The PBUSH attribute of the spring element can give the stiffness in 6 directions (three axial degrees of freedom, three rotational degrees of freedom). Due to the positional symmetry of the steel balls, the same stiffness coefficient is assigned to each group of springs, so that the four sets of springs have 24 degrees of freedom.

It is important to note that the CBUSH element needs to specify the local coordinate system, that is, the above six DOF directions are for the local coordinate system in which the CBUSH element is located. As the CBUSH element requires stiffness and damping parameters to represent the contact relationship, how to get the kinetic parameters of the junction becomes the key technology of the modeling method. The follow-up content will elaborate the method of combining the finite element method and the experiment to combine the dynamic parameter identification method.

\section{Experiments}

3.1. Modal Experiment of Car Seat Rail. The purpose of this modal experiment is to obtain the information of modal natural frequency, vibration mode, and damping ratio, which can provide reference for the revision of finite element calculation model by experimentally testing and analyzing a certain type of vehicle seat rails. It is necessary to determine the support mode, the excitation mode, the excitation point, and the response point in the modal experiment. The DH5927 dynamic testing and analysis equipment, threeway acceleration sensor, and impact hammer were used in modal experiment. The excitation adopts the hammering method. The excitation signal produced by the hammer has the advantage that the bandwidth of the signal can be controlled by different materials of the hammer. The higher the material stiffness, the wider the pulse signal spectrum will be. The adequate bandwidth can get more modes in one time. The hammering method is fixing the response point and moving the thumping point to compensate for the shortage of the number of acceleration sensors. For the excitation points and response points, the selected response points can reflect the basic outline of the specimen, while the nodes of main vibration modes should be avoided, and the test point which may have more local modes should be encrypted. In this modal experiment, four acceleration sensors are arranged. The transfer function is tested by moving the excitation point and fixing the response point.

According to vibration mechanics, the vibration of the structure is mainly due to the low-order natural frequency and its vibration mode. Due to the influence of the damping in the actual structure, the vibration modes of the higherorder frequencies will decay rapidly. In addition, when the sensitive frequency of the guide is less than $40 \mathrm{~Hz}$, the first and second natural frequency and vibration mode can be found and used as the optimization target in stiffness optimization.

Table 1 shows the natural frequency of the experimental mode. Figure 2 shows the steady-state experiment of a certain
TABLE 1: Natural frequency and damping coefficient.

\begin{tabular}{lccc}
\hline Order Frequency $(\mathrm{Hz})$ & Damping ratio (\%) & Mode of vibration \\
\hline 1 & 7.22 & 3.74 & Torsion of outer rail \\
2 & 12.65 & 2.57 & Swing of Internal rail \\
\hline
\end{tabular}

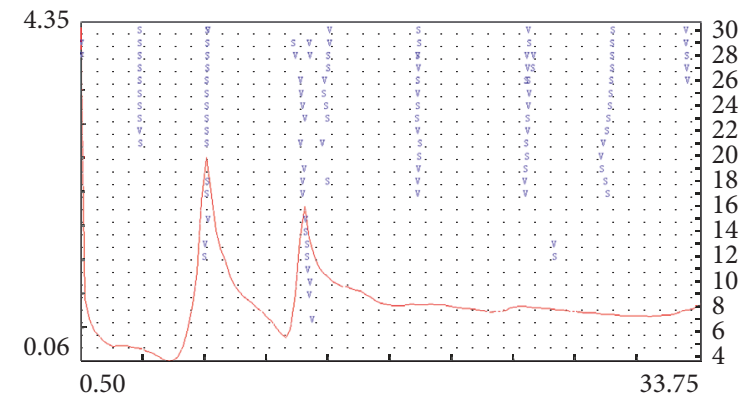

$(\mathrm{Hz})$

FIGURE 2: The stable diagram of the mode experiment for a certain point of force hammer.

point hammer excitation mode experiment. Figure 3 is the first and second modes of the experimental mode.

3.2. Frequency Sweep Experiment of Car Seat Rail. The purpose of this experiment is to obtain the time-acceleration curve of the excitation point and the time-acceleration response curve of the characteristic node by sweeping a certain type car seat rail, which provides the basis for the optimization of contact damping in finite element calculation. The DH5927 dynamic test and analysis system, three-way acceleration sensor, and HEV-20 exciter were used in modal experiment. There are 5 experimental output points, of which three time-acceleration curves will be used to fit the results of the finite element analysis output, and the remaining two points are used to validate the fitted parameters. The selection and installation of the sensor have a significant impact on the measurement results. The sensor should be installed in the condition of sufficient rigidity and without increasing the structural quality and then measure the true direction of the vibration signal. The excitation source of the sweep experiment needs to meet the following conditions: the amplitude level should satisfy certain conditions and the component being excited should have anti-interference ability when the exciter has tiny nonlinear behavior. In engineering fields, the sinusoidal signal is often chosen as the excited signal. The excited point selects the bolt installation hole at the bottom of the guide rail, which is consistent with the excited point in the practical working condition of the guide rail. The rails are suspended using a flexible rope during the entire excitation to simulate the unrestrained state.

The frequency sweep experiment uses the exciter as a frequency generator. As the exciter and the track are composed of open-loop system, it can be seen that the collected excitation and response signals have a significant signal amplification at the resonance, as shown in Figure 4, 


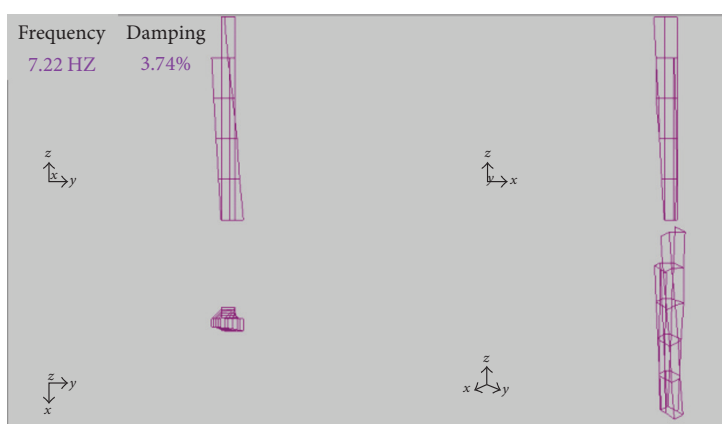

(a) The mode shape of first order

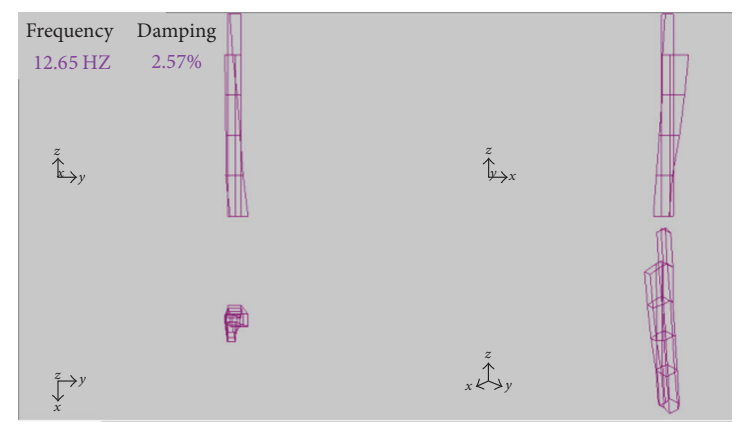

(b) The mode shape of second order

Figure 3

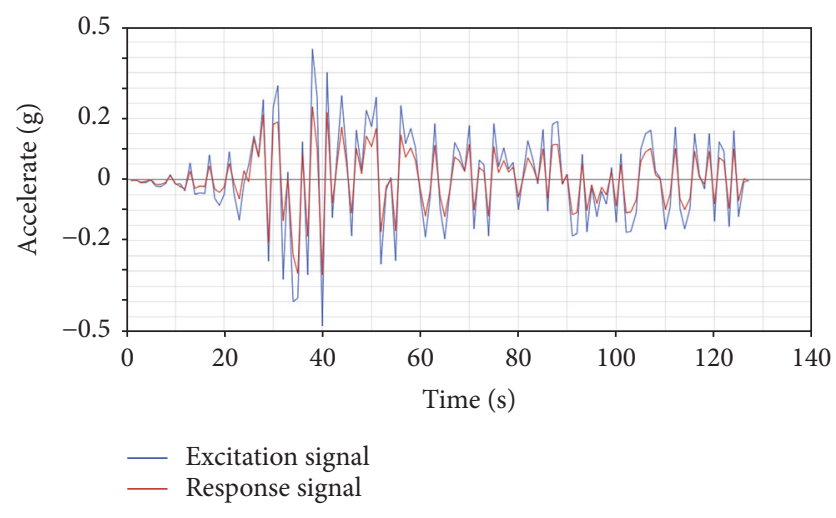

FIGURE 4: Excitation/response signal collected by frequency sweep experiment. The abscissa is for the sweep time (s), and the vertical axis is for the excitation amplitude (g).

in which the red signal is the response signal and the blue one is the excitation signal.

\section{Research on Modeling of Car Seat Rail Joint}

Based on the above two experiments, the stiffness and damping of the spring-damper element embedded in the joint part are optimized using OptiStruct and HyperStudy of FEM software. The equivalent contact stiffness and damping obtained from optimization characterize the contact properties in the joint part and thus allow us to establish a more accurate dynamic model of vehicle seat guide.

4.1. Least Squares Method and Curve Fitting. The least squares method is a kind of technique of mathematical optimization, minimizing the sum of squares of errors to find the best function of the data match [5]. Unknown data can be easily obtained using the least squares method, and the sum of the squares of the errors between the obtained data and the actual data can be minimized. The least squares method can also be used for curve fitting, and some other optimization problems can also be expressed by least squares by minimizing energy or maximizing entropy.

The specific approach to data fitting is as follows: for the given data $\left(x_{i}, y_{i}\right)(i=0,1, \ldots, m)$, finding $p(x) \in \Phi$ in the function class $\Phi$, minimizing the sum of square the error $r_{i}=$ $p\left(x_{i}\right)-y_{i}(i=0,1, \ldots, m)$,

$$
\sum_{i=0}^{m} r_{i}^{2}=\sum_{i=0}^{m}\left[p\left(x_{i}\right)-y_{i}\right]^{2}
$$

In the geometric sense, it means searching for the curve $y=p(x)$, which of the square sum of the distance from the given point $\left(x_{i}, y_{i}\right)(i=0,1, \ldots, m)$ is minimum (see Figure 5).

The function $p(x)$ is called the fitting function or the least squares solution. The method of finding the fitting function $p(x)$ is called the least squares method of curve fitting.

Polynomial Fitting. Given the data point $\left(x_{i}, y_{i}\right)(i=0,1$, $\ldots, m), \Phi$ is a function class consisting of polynomials whose number does not exceed $n(n \leq m)$.

Solve formula

$$
p_{n}(x)=\sum_{k=0}^{n} a_{k} x^{k} \in \Phi
$$

to make

$$
I=\sum_{i=0}^{m}\left[p_{n}\left(x_{i}\right)-y_{i}\right]^{2}=\sum_{i=0}^{m}\left(\sum_{k=0}^{n} a_{k} x_{i}^{k}-y_{i}\right)^{2}=\min .
$$

The general method of polynomial fitting can be summarized as follows:

(1) Use the known data to draw a rough graphic of functions-Scatter plot-to determine the number of times of fitting polynomials.

(2) Calculate

$$
\begin{gathered}
\sum_{i=0}^{m} x_{i}^{j} \quad(j=0,1, \ldots, 2 n) \\
\sum_{i=0}^{m} x_{i}^{j} y_{i} \quad(j=0,1, \ldots, 2 n) .
\end{gathered}
$$

(3) Write a formal equation and find $a_{0}, a_{1}, \ldots, a_{n}$. 
TABLE 2: The natural frequency of the rail model after optimization.

\begin{tabular}{lccc}
\hline Order & Experimental values $(\mathrm{Hz})$ & Optimization value $(\mathrm{Hz})$ & Vibration mode \\
\hline 1 & 7.22 & 7.220026 & Torsion of outer rail \\
2 & 12.65 & 12.65000 & Swing of Internal rail \\
\hline
\end{tabular}

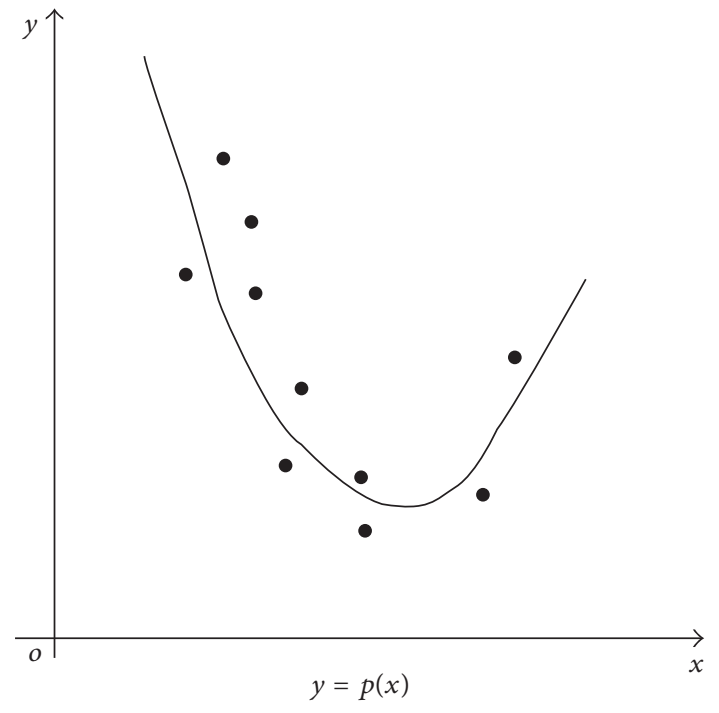

FIGURE 5

(4) Write the fitting polynomial:

$$
p_{n}(x)=\sum_{k=0}^{n} a_{k} x^{k}
$$

4.2. Stiffness Optimization of Car Seat Rail Joint. Under the OptiStruct in HyperWorks, the Lanczos method is used to extract the real eigenvalues of free modal for guide rail model by mass matrix normalization. In the initial analysis, a set of initial stiffness values are given for the spring, in which the rail calculation mode is in the same order of magnitude as the experimental mode natural frequency. The modal results are found to be not sensitive to the four sets of rotation angles, freedom, and stiffness, so only the stiffness of four axial displacements of these springs is considered. When the 12 rigidities are specified as $500 \mathrm{~N} / \mathrm{m}$, the first and second mode natural frequency of the guide rail system is given in Table 1 in the previous chapter.

In the OptiStruct module, the stiffness of the spring element is taken as the design variable and the least squares method is used to optimize the stiffness.

(1) Design Variable. The design variables are the stiffness of the joint to be optimized, that is, $\vec{K}_{x}, \vec{K}_{y}$, and $\vec{K}_{z}$ of the four springs, with 12 design variables. According to engineering experience, the design range of the stiffness is set to $1 \mathrm{~N} / \mathrm{m}$ to $1000 \mathrm{~N} / \mathrm{m}$, and the initial stiffness value is $500 \mathrm{~N} / \mathrm{m}$.
TABLE 3: Contact stiffness parameter after optimization (N/m).

\begin{tabular}{lccc}
\hline Number of Spring group & $X$ direction & $Y$ direction & $Z$ direction \\
\hline 1 & 205.5 & 155.2 & 158.3 \\
2 & 223.3 & 151.9 & 154.7 \\
3 & 201.3 & 152.1 & 152.9 \\
4 & 205.0 & 155.7 & 155.9 \\
\hline
\end{tabular}

(2) Design Objective. Using the least squares method to minimize the objective function:

$$
\min f\left(f_{1}, f_{2}, \ldots, f_{n}\right)=\sqrt{\sum_{i=1}^{n}\left(F_{i}-f_{i}\right)^{2}}
$$

where $F_{i}$ is the natural frequency of the experimental mode and $f_{i}$ is the natural frequency of the modal.

(3) Analysis of Optimization Results. After optimization, the least squares deviation of the objective function is $2.59 e^{-5}$. The optimized natural frequency is shown in Table 2 , and the spring stiffness is shown in Table 3.

After comparison, the optimized vibration mode of the guide rail system coincides with the corresponding vibration mode of the experimental mode, so we believe that the optimized spring stiffness is the equivalent contact stiffness of the joint to be obtained.

4.3. Damping Optimization of Car Seat Rail Joint. The timedomain signal of the excitation and response of the sweep test is obtained in the previous section, as shown in Figure 4. In order to be able to compare with the experimental results, the excitation signal in Figure 4 is used as the excitation signal in the finite element software, and the transient analysis is carried out using the OptiStruct solver. The selection of the excitation point and the response point corresponds to their position in the actual sweep test. In the first calculation, the initial value of the structural damping is specified as 0.2 and the initial value of the contact damping is set to 2 . As shown in Figure 6, the results of finite element calculation are output under the excitation signal excitation given in Figure 4.

The red curve is the time-acceleration response signal getting from software before optimization, and the blue curve is the experimental response signal after sparse processing in Figure 4.

It can be seen that the peaks of these two curves are close to each other. The finite element calculation curves are well consonant with the test data. On the other hand, the previous optimization of the binding site of the stiffness value is consistent with the actual rail. 
TABLE 4: The data sheet of design variable (Ns/m).

\begin{tabular}{|c|c|c|c|c|}
\hline Design variable & Notes & Lower limit & Initial value & Upper limit \\
\hline G & Structural damping & 0.1 & 0.2 & 0.3 \\
\hline $\mathrm{C} 11$ & $x$ directions of first set & 0.2 & 2 & 20 \\
\hline $\mathrm{C} 12$ & $y$ directions of first set & 0.2 & 2 & 20 \\
\hline $\mathrm{C} 13$ & $z$ directions of first set & 0.2 & 2 & 20 \\
\hline $\mathrm{C} 21$ & $x$ directions of second set & 0.2 & 2 & 20 \\
\hline $\mathrm{C} 22$ & $y$ directions of second set & 0.2 & 2 & 20 \\
\hline $\mathrm{C} 23$ & $z$ directions of second set & 0.2 & 2 & 20 \\
\hline $\mathrm{C} 31$ & $x$ directions of third set & 0.2 & 2 & 20 \\
\hline $\mathrm{C} 32$ & $y$ directions of third set & 0.2 & 2 & 20 \\
\hline $\mathrm{C} 33$ & $z$ directions of third set & 0.2 & 2 & 20 \\
\hline C41 & $x$ directions of fourth set & 0.2 & 2 & 20 \\
\hline $\mathrm{C} 42$ & $y$ directions of fourth set & 0.2 & 2 & 20 \\
\hline $\mathrm{C} 43$ & $z$ directions of fourth set & 0.2 & 2 & 20 \\
\hline
\end{tabular}

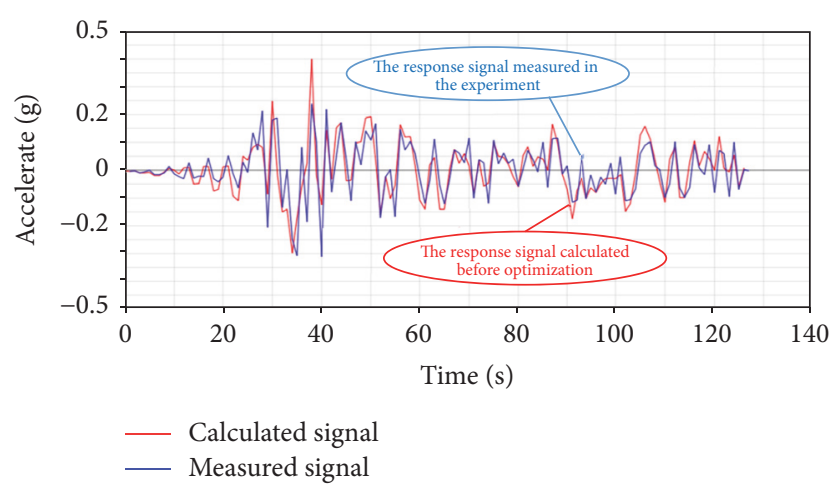

FIGURE 6: The output of the finite element calculation and experiment.

Then, we further fit the FE output to the experimental output curve to obtain a set of optimized damping coefficients, which is exactly the joint contact damping we are looking for. In HyperStudy curve fitting, we must explicitly design variables, objective function, design goals, and other objects.

(1) Design Variables. There are structure damping coefficient and damping coefficient of three directions in four sets of spring, which have 13 design variables. The initial damping value of a given structure is 0.2 , and the variation range is 0.1 to 0.3 . The spring-damping coefficient is set to 2 and the range of variation is 0.2 to 20 . Table 4 lists the specific values.

Four sets of spring have been defined in the model as shown in Figure 1(b). In Table 4, "G" is the structural damping, and "C" is the damping of the three directions $(x$, $y, z)$ in four sets of spring.

(2) Objective Function. Using the least square method as the objective function:

$$
\mathrm{OBJ}=\frac{\sum_{i=1}^{127}\left(y_{i} / \eta_{i}\right)^{2}}{127}
$$

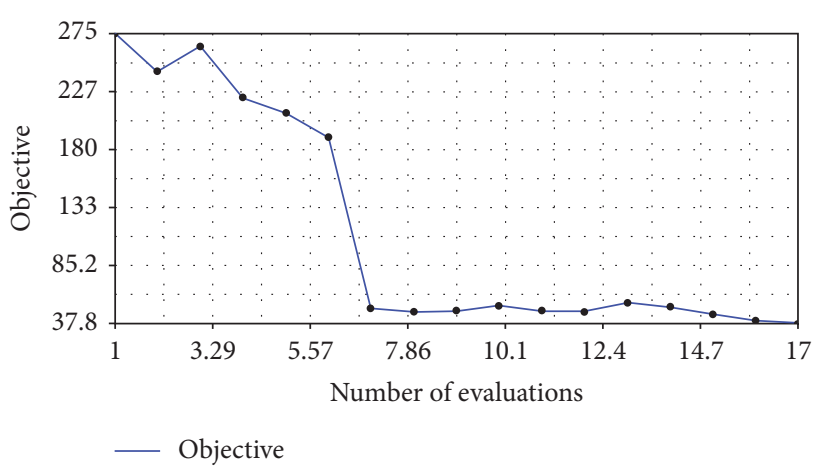

FIgURE 7: The convergent curve of the objective function.

where $y_{i}$ is the displacement response of the corresponding points on the response curve of the finite element result.

$\eta_{i}$ is the displacement response of each point after sparse processing.

$i=1,2, \ldots, 127$ (there are 127 points in the curve).

(3) Design Objective. Minimize the objective function: $\min (\mathrm{OBJ})$.

According to the objective function, the target value OBJ before optimization is 274.64. After HyperStudy optimization, the target OBJ reduces to 37.81. The number of iterations is 17 as shown in Figure 7. The finite element calculation response curve is further approximated to the experimental output curve as shown in Figure 8.

The blue curve is the experimental response signal after sparse processing in Figure 4. The green curve is the timeacceleration response signal getting from software after optimization.

After optimization is completed, the optimal solution of a set of contact damping is shown in Table 5 .

So far, the contact stiffness and contact damping of the joint of the rail model are all optimized, and the finite element model is reestablished based on the optimized contact damping and contact stiffness. The relative displacement between the two ends of the spring element can be output by the 


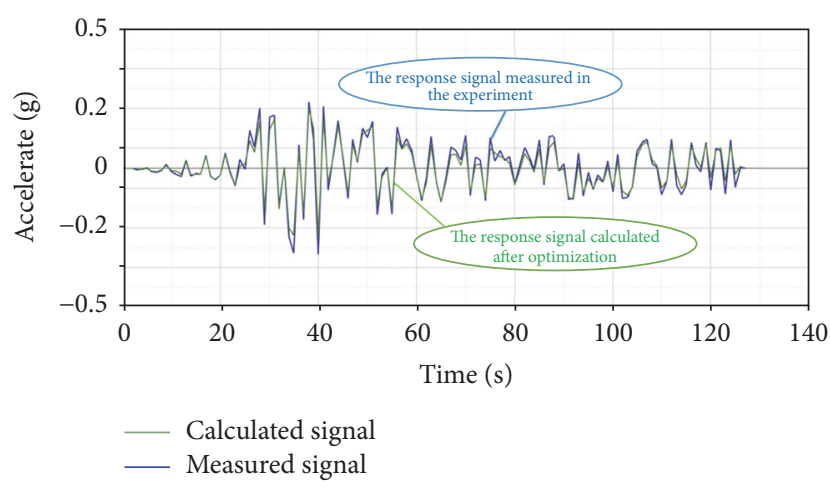

FIGURE 8: The optimized output and experimental output of the finite element software.

TABLE 5: Results of damping optimization (Ns/m).

\begin{tabular}{lccc}
\hline Number of spring group & $X$ direction & $Y$ direction & $Z$ direction \\
\hline 1 & 14.2 & 3.4 & 4.7 \\
2 & 17.3 & 13.7 & 1.8 \\
3 & 2.7 & 9.5 & 1.3 \\
4 & 6.1 & 19.1 & 5.3 \\
\hline
\end{tabular}

appropriate excitation signal to the guide rail model, which is between the steel ball and the inner/outer rail.

\section{Discussion}

5.1. Gap Evaluation of Car Seat Rail Joint under Uncertain Excitation. Under uncertain external loads which depend on time-domain or frequency domain, the spring-damper element embedded in the joint part will behave irregularly, resulting in a gap. In order to statistically analyze the confidence interval of the gap, the transient analysis can be carried out on the dynamic model of the guide rail, and the gap of the guide joint is studied using statistical method. The frequency response analysis is used to verify the results. Finally, the interval confidence intervals of the joints are calculated under dynamic excitation. Seat mass is converted to forces which are applied to both ends of the rail and the excitation location, as shown in Figure 9.

Gap calculation formula:

$$
\operatorname{gap}=\sum_{i=1}^{20} \frac{\vec{v}_{i-} A-\vec{v}_{i-B}}{20}
$$

where $\vec{v}_{i-} A$ and $\vec{v}_{i} B$ represent the time domain or frequency response of displacement of two terminal points of CBUSH unit, respectively, and 20 is the number of $\mathrm{CBUSH}$ units, that is, the number of the replaced steel balls.

Figure 9 (a) shows that the seat quality is converted into force to be applied to the position where the guide rail is connected with the seat. The whole chair weighs $12 \mathrm{KG}$ and is evenly distributed on both side rails; then one side rail is subjected to $60 \mathrm{~N}$ vertical force. Both ends are connected. Figure 9(b): Because the signal phase difference has little influence on the vibration amplitude, the same excitation
TABLE 6: Interval confidence table.

\begin{tabular}{lc}
\hline Confidence & Gap value \\
\hline $90 \%$ & $0.116 \mathrm{~mm}$ \\
$95 \%$ & $0.137 \mathrm{~mm}$ \\
$99 \%$ & $0.180 \mathrm{~mm}$ \\
\hline
\end{tabular}

signal is adopted in the three mounting points, and the phase error of the excitation signal is not considered.

5.1.1. Evaluation Method of Seat Joint Gap Using Transient Analysis. As the amplitude of actual road conditions is random, the results of the road spectrum will reflect the actual rail gap situation more accurately. Therefore, the road spectrum of the rail- body-connection point is collected when the car is driving on the road, and the data is used as the excitation signal of the rails, as shown in Figure 10.

The $z$ direction excitation signal is applied to the connecting position of the guide rail and the vehicle body. As the excitation of the road profile, the 20 pairs of spring ends inserted in the inner joint of the guide rail are inevitably dislocated, and the relative displacement between the two ends of the 20 sets of springs can be obtained, as shown in Figure 11. Point A is a node that connects directly to the inner rail, while point $\mathrm{B}$ is a node that connects the outer rail.

It is shown that the maximum value of the gap is $0.23 \mathrm{~mm}$ in the time-history curve with the time span of 100 seconds. In order to further determine the confidence interval of the seat guide gap, the relative displacement between the two ends of 20 springs in Figure 6 is calculated. Each curve outputs 400 points evenly, and 8000 points of the 20 curves constitute our statistical sample space. In Figure 12, the ordinate values of 8000 points are illustrated.

Figure 12(a) is the relative displacement of the two ends of the spring distribution histogram. According to the mathematical statistics, the data of this group obey $N(0.00027$, 0.0701); we can see that the gap we are concerned with is only limited to the right half of the normal distribution. Figure 12(b): The left part of the ball is actually pressed by the situation.

Since Figure 12(b) is half of the normal distribution, the mean value of this part can be obtained easily, which is $0.028 \mathrm{~mm}$. Therefore, the mean value of the gap is $0.028 \mathrm{~mm}$. From the mathematical statistics it can be seen that the probability density function of the branch is twice the normal distribution probability density function, but the range of $x$ is 0 to $+\infty$.

According to the normal distribution table, $90 \%$ of the grasp of the gap does not exceed $0.116 \mathrm{~mm}$; $95 \%$ of the grasp of the gap does not exceed $0.137 \mathrm{~mm}$; $99 \%$ of the grasp of the gap does not exceed $0.180 \mathrm{~mm}$, as shown in Table 6 .

5.1.2. Evaluation Method of Seat Joint Gap Using Frequency Response Analysis. The conversion from the time domain to 


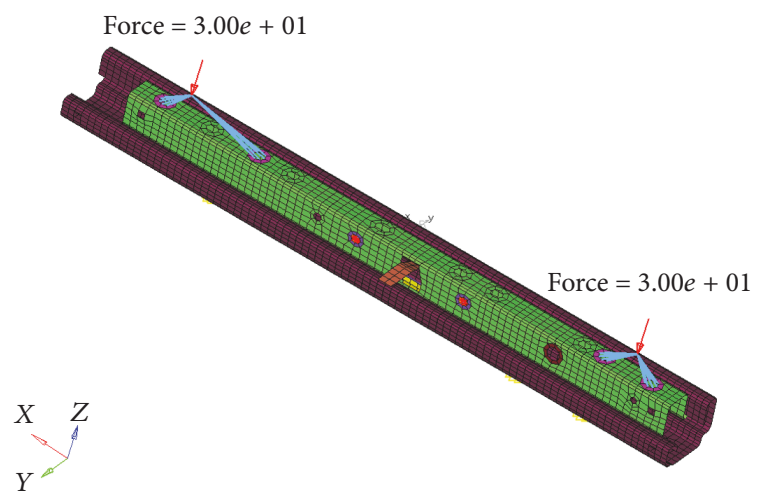

(a) Seat position

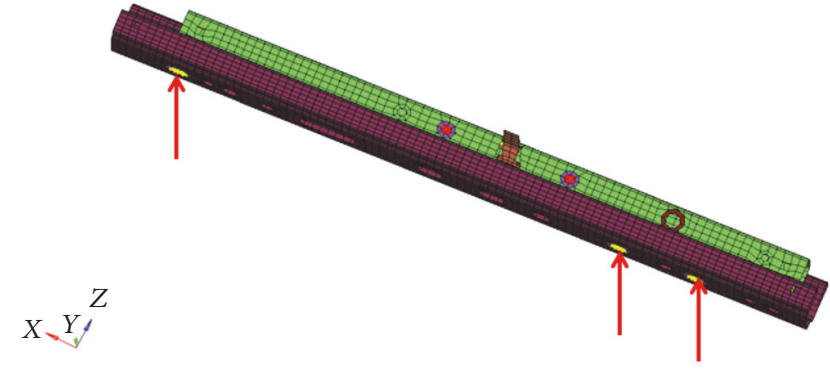

(b) Excitation location

FIGURE 9

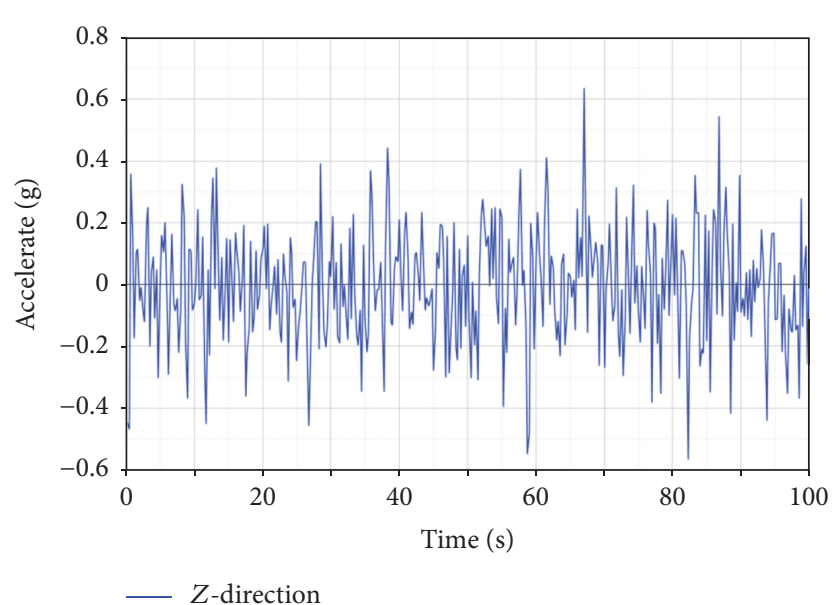

FIGURE 10: The $z$ direction spectrum collected when the vehicle speed is $60 \mathrm{~km} / \mathrm{h}$.

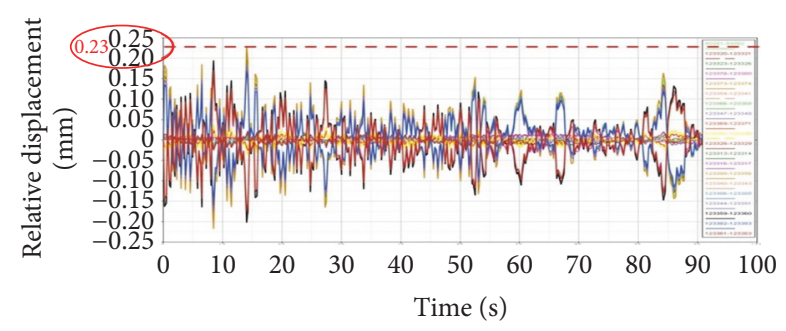

FIGURE 11: The relative displacement-time curve of the two ends of the spring under the excitation of $60 \mathrm{~km} / \mathrm{h}$.

the frequency domain signal requires a Fourier transform. The ideal Fourier transform is defined as follows:

$$
\begin{aligned}
X(\omega) & =\int_{-\infty}^{\infty} x(t) e^{-j \omega t} d t \\
& =\sum_{n=-\infty}^{\infty} x(n \Delta t) e^{-j 2 \pi k \Delta f n \Delta t} \Delta t .
\end{aligned}
$$

Since the idealized Fourier transform is not windowed, the time is considered to be from negative infinity to positive infinity, which leads to an increase in the magnitude of the frequency domain by $N$ times the number of timedomain signal samples. In addition, the Fourier transform is a bilateral spectrum, but, in reality, we only take part of the frequency greater than zero. In order to compensate for the loss of energy, the amplitude of the unilateral spectrum needs to be doubled. The sampling time-domain signal ranges from 0 to the end of time $T$, which is the ideal signal plus a rectangular window. The definition formula is

$$
X(\omega)=\int_{0}^{T} x(t) e^{-j \omega t} d t=\int_{-\infty}^{\infty} w_{R}(t) x(t) e^{-j \omega t} d t,
$$

where $w_{R}$ is the window function and the rectangular window can be defined as

$$
w_{R}(t)=\left\{\begin{array}{ll}
1, & t \in[0, T] \\
0, & t \notin[0, T]
\end{array} .\right.
$$

The relationship between the Fourier transform and the ideal Fourier transform, which have practical engineering significance, is

$$
\text { Engineering_FFT } \mathrm{Fmg}_{\text {mag }}=\frac{|\mathrm{FFT}|}{N} \times 2 .
$$

Figure 13(a) is the frequency domain signal after the engineering Fourier transform for the excitation signal shown in Figure 10; Figure 13(b) is the frequency-acceleration curve of the low frequency band. The maximum amplitude of the Fourier transform of the excitation signal is $0.0134 \mathrm{~g}$, or $0.134 \mathrm{~m} / \mathrm{s}^{2}$.

According to Figure 13, since the response of the frequency excitation will only amplify significantly at the resonant point, statistical methods such as transient response analysis will be meaningless. In addition, vibration mechanics is based on the assumption of linear small deformation, so you can use the amplitude of 1 unit sinusoidal excitation A on the track for frequency response analysis; then you can extract the peak value of the gap $\delta_{A}$ between the two ends of the spring. The peak of the gap is

$$
\delta_{B} \leq \delta_{A} \cdot \max [B(\omega)]
$$




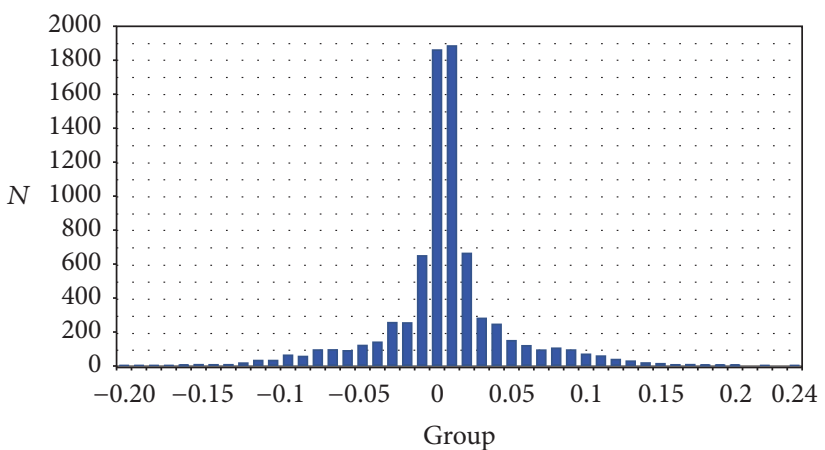

Relative disp

(a) The distribution of relative displacement

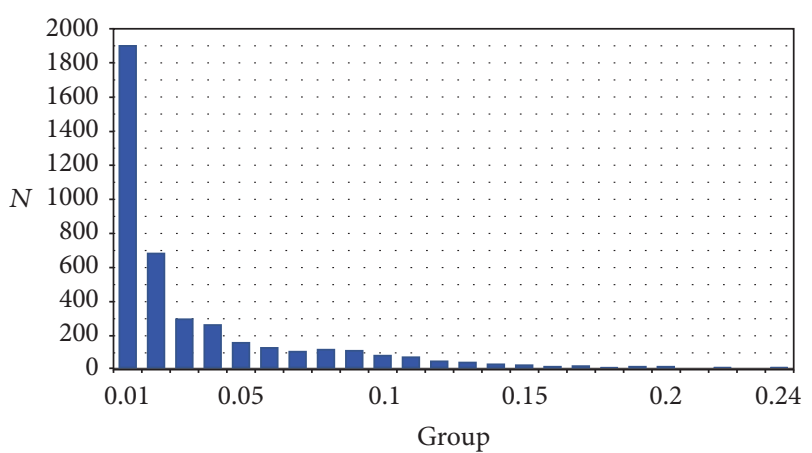

Relative disp

(b) The distribution of gap interval

Figure 12

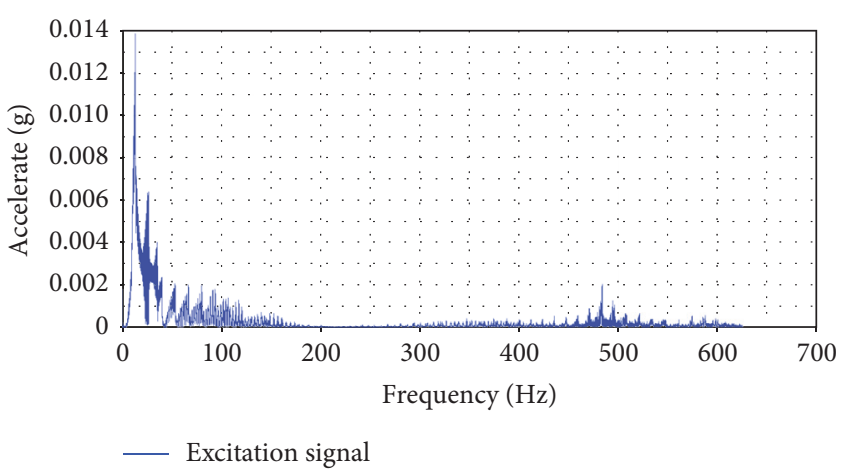

(a) Frequency domain signal after Fourier transform

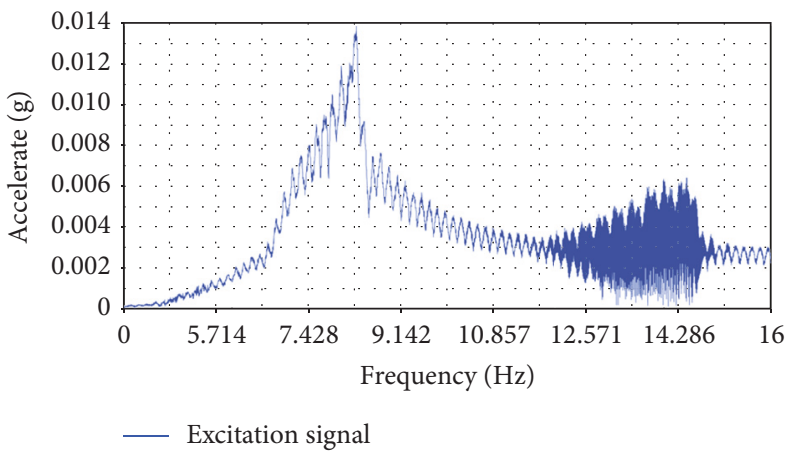

(b) Low frequency domain signal

Figure 13

According to formula (13), frequency response excitation is carried out in the same excitation position with a unit sinusoidal excitation (amplitude of $1 \mathrm{~mm} / \mathrm{s}^{2}$ ), and sweep frequency range is $4 \sim 36 \mathrm{~Hz}$. The curve of relative displacement between the two ends of the spring with frequency is shown in Figure 14.

It can be seen that the maximum relative displacement of the two ends of the spring is $A=0.000176 \mathrm{~mm}$ under the unit sinusoidal excitation with amplitude of $1 \mathrm{~mm} / \mathrm{s}^{2}$.

Substituting formula (13):

$$
\begin{aligned}
\delta_{B} & \leq \delta_{A} \cdot \max [B(\omega)]=0.000176 \times 134 \\
& =0.0236 \mathrm{~mm} .
\end{aligned}
$$

Thus, the peak value of the time-domain signal shown in Figure 11 is $0.76 \mathrm{~g}$. After the Fourier transform, the excitation peak at the resonant point is $0.0134 \mathrm{~g}$, and the resulting gap does not exceed $0.0236 \mathrm{~mm}$. When the frequency excitation peak is $1 \mathrm{~m} / \mathrm{s}^{2}$ :

$$
\begin{aligned}
\delta_{B} & \leq \delta_{A} \cdot \max [B(\omega)]=0.000176 \times 1000 \\
& =0.176 \mathrm{~mm} .
\end{aligned}
$$

The results show that when the frequency excitation amplitude is $1 \mathrm{~m} / \mathrm{s}^{2}$, the gap will not exceed $0.176 \mathrm{~mm}$.

\subsection{Gap Evaluation of Car Seat Rail Joint under Uncertain Structure}

5.2.1. Screening Influence Factors of Gap in Seat Rail Joint. In order to study the influence of eight factors on the gap of the joint, experiments need to be designed to screen out the factors that have an important impact to focus on inspection. The first-round selection is determined by using the Hammersley design method, which is uniform and robust in multidimensional problems. The values of each factor are interval uncertain values, which belong to an infinite number of theoretical levels. The optimization problem is defined in HyperStudy, including defining eight factors as design variables and assigning the initial value and the upper and lower limits, as shown in Table 7.

As can be seen from Figure 13, the random excitations in the time domain are applied. In a transient analysis, the relative displacement of the balls assumes a normal distribution. For a normal distribution, the confidence can be predicted from the mean and the equation. In a similar way, when considering a random structure, four responses, as shown in Table 7, which correspond to $90 \%, 95 \%, 99 \%$, and $100 \%$ confidence in the case of random loads, can be defined as the relative displacement. In a transient analysis, all four responses are deterministic, but after a set of randomized 
TABLE 7: Valve table of experimental design variable.

\begin{tabular}{lcccc}
\hline Factor & Notes & Lower limit & Initial value & Upper limit \\
\hline$t_{-}$up & Internal rail thickness $(\mathrm{mm})$ & 1.30 & 1.40 & 1.50 \\
$t$ _down & Outer rail thickness $(\mathrm{mm})$ & 1.30 & 1.40 & 1.50 \\
$E$ & Elastic modulus of guide material $(\mathrm{Mpa})$ & 200000 & 210000 & 0.3 \\
$\mathrm{nu}$ & Poisson's ratio of guide material & 0.27 & $7.80 e-9$ & 0.33 \\
$\rho$ & Guide material density $\left(\mathrm{T} / \mathrm{mm}^{3}\right)$ & $7.70 e-9$ & 0 & 0 \\
$r$ up & Ridge radius of inner rail $(\mathrm{mm})$ & -1 & 0 & 1 \\
$r$ down & Ridge radius of outer rail $(\mathrm{mm})$ & -1 & 0 \\
$d$ & Manufacturing error of ball diameter $(\mathrm{mm})$ & & 1 \\
\hline
\end{tabular}

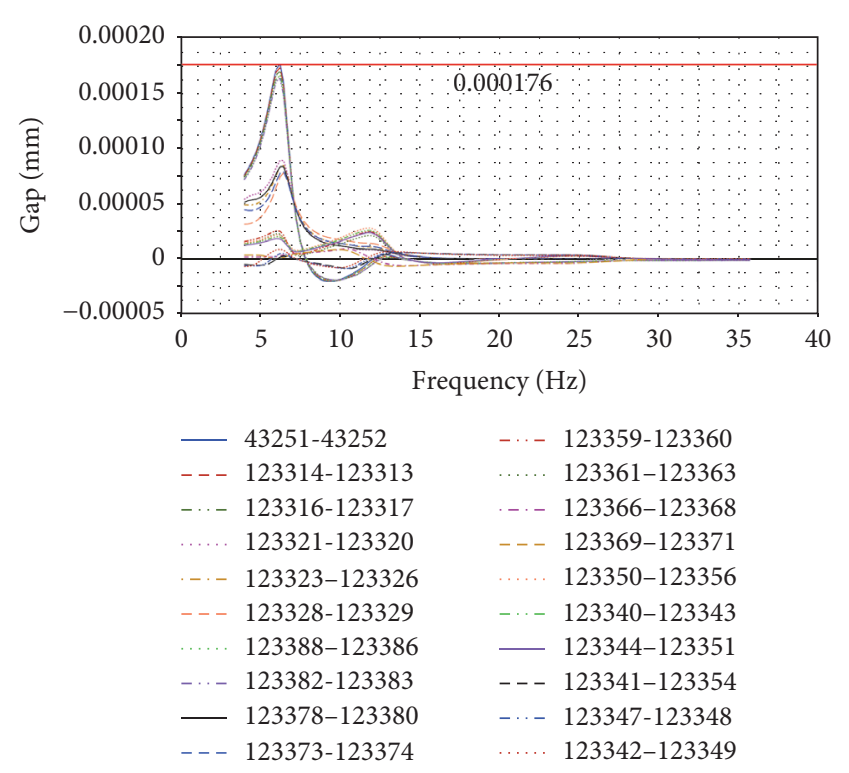

FIGURE 14: The relative displacement-frequency curve of the two ends of the spring.

studies based on the response surface, these four responses show some distribution.

In Table $8, \vec{v}_{i} A$ and $\vec{v}_{i} B$ represent the displacement response of the spring-damper element to the inner and outer rail joints, respectively, expressed in a one-dimensional vector. $t_{-}$up ${ }^{\prime}$ and $t_{-}$down' ${ }^{\prime}$ are the inner and outer rail thickness after deformation. $N$ represents the total number of points in the time course; sum and sqrt are the one-dimensional vector summation and the root function, respectively. In addition, gap represents the maximum gap, meaning the maximum value of the gap in one transient analysis. The other three are $99 \%, 95 \%$, and $90 \%$ of the gap, and the confidence value is $99 \%$. For example, in a transient analysis, the gap in the time domain is $99 \%$ may not exceed this value. The other three responses can be studied in the same way.

After the design variables and response definitions are complete, the main effect is calculated using the DOE method of the Hammersley sampling design, and several factors that have the greatest effect on the response are selected as shown in Figure 14. Table 9 lists the main effects of the Hammersley sampling design (Figure 15).

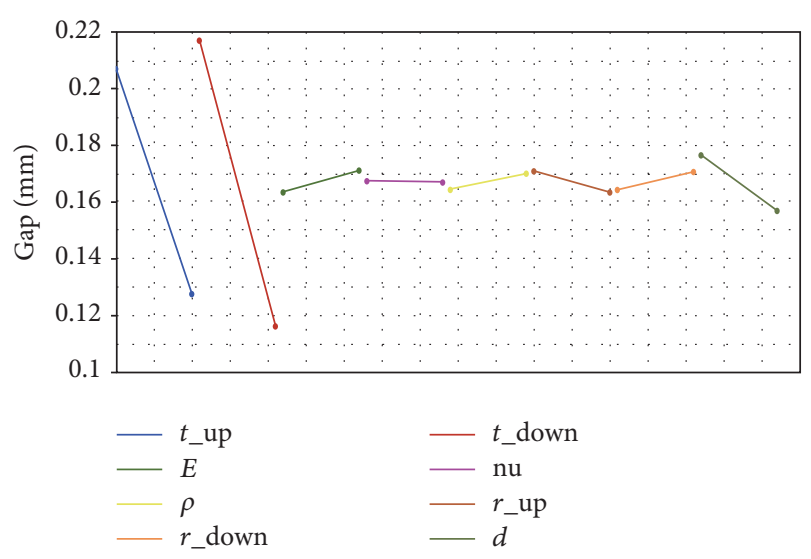

FIGURE 15: The schematic diagram of the main effect of the design of the Hammersley sampling.

It can be determined that the inner rail thickness ( $t_{-}$up), the outer rail thickness ( $t_{-}$down), and the ball diameter manufacturing error $(d)$ have an important effect on the response $\left(\mathrm{gap}_{\max }\right)$.

5.2.2. The Random Structure Distribution under Different Excitation Confidences. The internal rail thickness ( $t_{-}$up), outer rail thickness ( $t_{-}$down), and ball diameter manufacturing error $(d)$ as design variables, to meet the normal distribution, are shown in Table 10.

According to the distribution of the parameters in Table 10, the Hammersley samples were used to generate a set of 1000 combinations of design variables to extract the response values, and four confidence intervals were obtained.

Under a transient load, the clearance corresponding to the outside confidence is defined as shown in the definition in Table 8. In a set of randomness studies based on the response surface, the gap will exhibit some distribution. The random distribution of gaps and the confidence table are shown in Figure 16.

Figure 16 shows the stochastic distribution of 90, 95\%, $99 \%$, and $100 \%$ confidence intervals of random load. Combining the above studies, considering the joint distribution of load and structure random, the joint confidence interval joint table can be obtained, as shown in Table 11.

It can be seen that with the increase of the load confidence and the structural confidence, the joint gap tends to increase, 
TABLE 8: Gap responses of different confidences.

\begin{tabular}{lcc}
\hline Response & Confidence & \\
$\operatorname{gap}_{\mu+1.65 \sigma}$ & $90 \%$ & $\operatorname{gap}_{\mu+1.65 \sigma}=\frac{\operatorname{sum}\left(\vec{v}_{i_{A}}-\vec{v}_{i_{B}}\right)}{N}+1.65 *\left(\frac{\operatorname{sqrt}\left(\operatorname{sum}\left(\left(\left(\vec{v}_{i_{A}}-\vec{v}_{i_{B}}\right)-\operatorname{sum}\left(\vec{v}_{i_{A}}-\vec{v}_{i_{B}}\right) / N\right)^{2}\right)\right)}{N}\right)$ \\
$\operatorname{gap}_{\mu+1.96 \sigma}$ & $95 \%$ & $\operatorname{gap}_{\mu+1.96 \sigma}=\frac{\operatorname{sum}\left(\vec{v}_{i_{A}}-\vec{v}_{i_{B}}\right)}{N}+1.96 *\left(\frac{\operatorname{sqrt}\left(\operatorname{sum}\left(\left(\left(\vec{v}_{i_{A}}-\vec{v}_{i_{B}}\right)-\operatorname{sum}\left(\vec{v}_{i_{A}}-\vec{v}_{i_{B}}\right) / N\right)^{2}\right)\right)}{N}\right)$ \\
$\operatorname{gap}_{\mu+2.58 \sigma}$ & $99 \%$ & $\operatorname{gap}_{\mu+2.58 \sigma}=\frac{\operatorname{sum}\left(\vec{v}_{i_{A}}-\vec{v}_{i_{B}}\right)}{N}+2.58 *\left(\frac{\operatorname{sqrt}\left(\operatorname{sum}\left(\left(\left(\vec{v}_{i_{A}}-\vec{v}_{i_{B}}\right)-\operatorname{sum}\left(\vec{v}_{i_{A}}-\vec{v}_{i_{B}}\right) / N\right)^{2}\right)\right)}{N}\right)$ \\
$\operatorname{gap}_{\max }$ & $100 \%$ & $\operatorname{gap}_{\max }=\max \left(\vec{v}_{i} A-\vec{v}_{i} B\right)-\left(\frac{t_{-} \text {up }}{2}+\frac{t_{\text {_down }}{ }^{\prime}}{2}-1.4\right)$ \\
\hline
\end{tabular}

TABLE 9: The sampling design and the main effect of the value of Hammersley.

\begin{tabular}{lc}
\hline Variable name & Main effect \\
\hline$t_{\text {_up }}$ & -0.08 \\
$t_{\text {_down }}$ & -0.101 \\
$E$ & 0.007 \\
$\mathrm{nu}$ & 0.001 \\
$\rho$ & 0.005 \\
$r_{\text {_up }}$ & -0.007 \\
$r_{\text {_down }}$ & -0.006 \\
$d$ & -0.02 \\
\hline
\end{tabular}

and the effect of the load uncertainty is greater than the structural uncertainty.

Based on the above conclusions, consider the gap value of $0.1968 \mathrm{~mm}$ as the recommended installation preload value, using $90 \%$ of the structure confidence external and $99 \%$ of the load confidence. The specific basis is as follows.

The impact of load uncertainty is higher than the degree of structural uncertainty, which can be key consideration.

In reality, structural uncertainty cannot be measured directly. It is difficult to accurately control.

In engineering fields, seat manufacturers preload the rail to the value of $0.2 \mathrm{~mm}$ when they solve the problem of abnormal noise, which also shows that the research work done in this paper accurately predicts the rail preload value, providing theoretical basis to solve this problem.

\section{Conclusions}

With passengers' increasing requirements of comfort, noise, vibration, and harshness (NVH) have become one of the major concerns of car manufacturers. In this paper, the study of the gap between the car seat rail joints is a componentlevel NVH problem. By studying the finite element dynamic model of the car seat rail joint, the problem of the gap distribution of the joint is analyzed according to a series of dynamic responses under the uncertainty of the external load. Furthermore, in the case that the structural parameters of the guide rail itself are uncertain, the randomness of the gap was also studied in this paper. The significance of this paper is predicting the distribution of gap in the joint of car seat guide rail by finite element simulation and providing the guiding value of installation preloading, which provides not only a solution but also the theoretical basis for field engineer to solve the problem of track abnormal sound.

The research results completed in this paper are listed as follows:

(1) Based on a certain model of car seat rail, the modal experiment and sweep experiment are carried out. Through these two experiments, the dynamic performance of the car seat guide is further studied.

(2) The finite element dynamic model of automobile seat rail is established in HyperMesh. The coupling part is embedded in a spring-damping unit, and the contact behavior of the joint is characterized by stiffness and damping. The stiffness and damping are optimized by the combination of experiment and finite element optimization software, so as to ensure the modeling accuracy of the finite element dynamic model.

(3) Under the condition that the external load of the seat rail is uncertain, a series of dynamic analyses of the guide rail is carried out. The joint gap is studied by the dynamic response of the spring-damping unit embedded in the joint. Then the reliable prediction of the gap is analyzed statistically, which is found to be $0.180 \mathrm{~mm}$. In other words, when considering the random load, it is recommended to preload $0.180 \mathrm{~mm}$ when the rail is installed.

(4) The dynamic behavior of the spring-damper element is studied under the consideration of the structural uncertainties of the guide rail itself. The authors use the DOE to screen out the important influence own uncertainty factors and then carry on the randomness research. The results show that the distribution of influencing factors has little effect on the final distribution of interfacial gap. 
TABLE 10: Random distribution table of design variables.

\begin{tabular}{lccc}
\hline Factor & Random distribution & Parameter $a(\mathrm{~mm})$ & Parameter $b\left(\mathrm{~mm}^{2}\right)$ \\
\hline$t_{-}$up & Normal distribution $\left(\mu, \sigma^{2}\right)$ & 1.40 & 0.0015 \\
$t_{-}$down & Normal distribution $\left(\mu, \sigma^{2}\right)$ & 1.40 & 0.0015 \\
$d$ & Normal distribution $\left(\mu, \sigma^{2}\right)$ & 0 & 0.1 \\
\hline
\end{tabular}

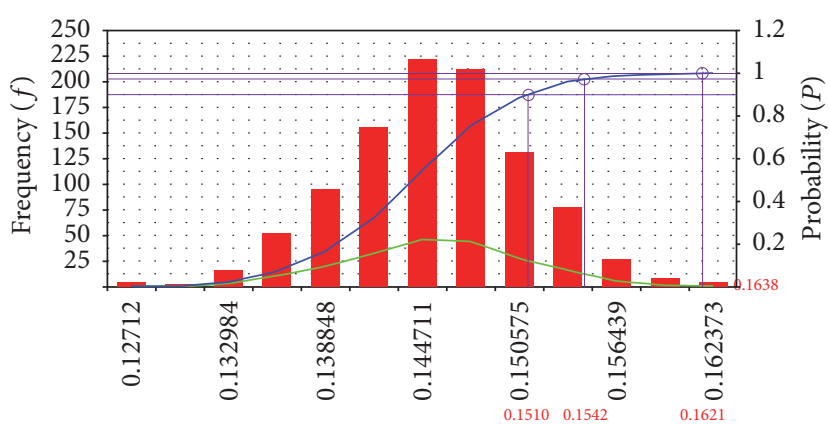

Histogram $(f)$

Probability density $(P)$

— Cumulative distribution $(P)$

(a) Random distribution of $\operatorname{gap}_{\mu+1.65 \sigma}$

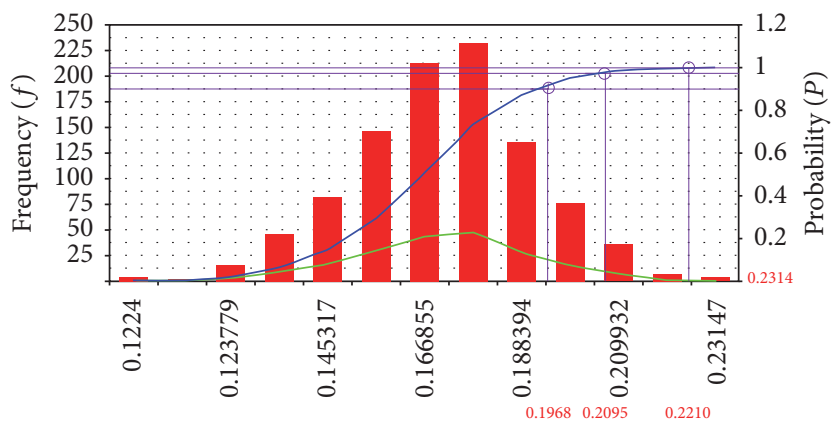

Histogram $(f)$

Probability density $(P)$

- Cumulative distribution $(P)$

(c) Random distribution of $\operatorname{gap}_{\mu+2.58 \sigma}$

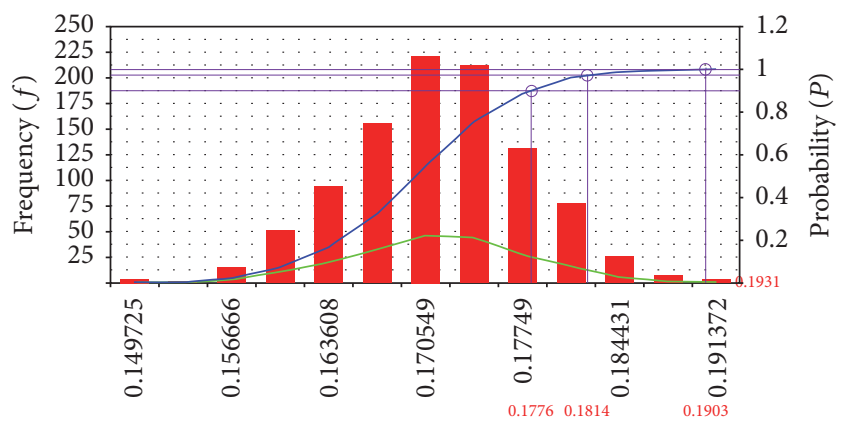

Histogram $(f)$

Probability density $(P)$

— Cumulative distribution $(P)$

(b) Random distribution of $\operatorname{gap}_{\mu+1.96 \sigma}$

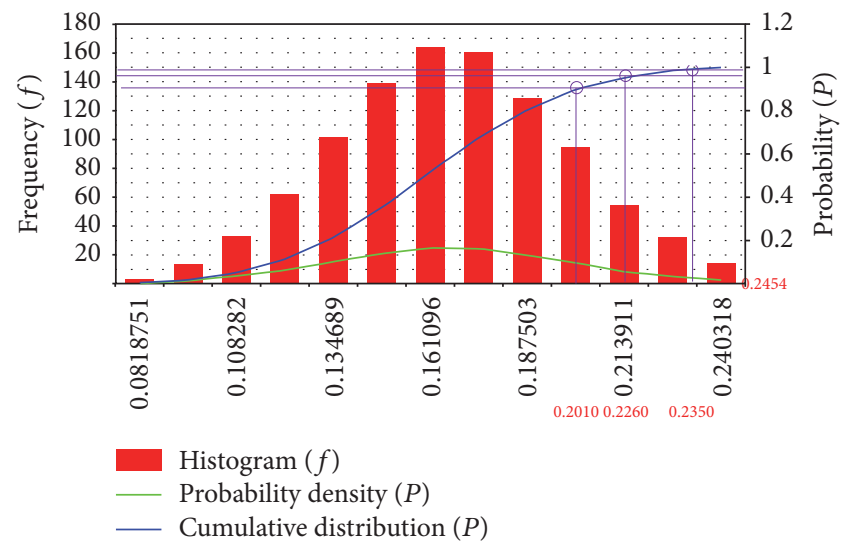

(d) Random distribution of gap max $_{\text {m }}$

FIGURE 16

TABLE 11: Confidences of junction gap (mm).

\begin{tabular}{lcccc}
\hline \multirow{2}{*}{ Load confidence } & \multicolumn{4}{c}{ Structural confidence External } \\
& $90 \%$ & $95 \%$ & $99 \%$ & $100 \%$ \\
\hline $90 \%$ & 0.1510 & 0.1542 & 0.1621 & 0.1638 \\
$95 \%$ & 0.1776 & 0.1814 & 0.1903 & 0.1931 \\
$99 \%$ & $\mathbf{0 . 1 9 6 8}$ & 0.2095 & 0.2210 & 0.2314 \\
$100 \%$ & 0.2010 & 0.2260 & 0.2350 & 0.2454 \\
\hline
\end{tabular}

(5) Based on the randomness study, the joint confidences are given under the influence of two kinds of uncertainties of load and structure. The reliable gap prediction value is $0.197 \mathrm{~mm}$. In other words, in considering the load and structural random factors, it is recommended to preload $0.197 \mathrm{~mm}$ when the rail is installed.

\section{Conflicts of Interest}

There are no conflicts of interest regarding the publication of this paper.

\section{Acknowledgments}

Thanks are due to the support of the Civil-Military Integration Project of Shanghai, no. 201643.

\section{References}

[1] L.-1. Zhang, "Analysis and Enlightenment of Global Automobile Industry Value Chain - Taking GM, Ford, Volkswagen and Toyota as examples," Value Engineering, vol. 3, pp. 47-49, 2006.

[2] J. He, G. Shen, and W. Tie-gang, "Visuality of NVH in Vehicle [J]," Bus Technology and Research, vol. 5, pp. 15-17, 2007. 
[3] J. Zhang, Optimization Design and Research of Powertrain Mounting System for Light Buses, Wuhan University of Science and Technology, Wuhan, China, 2013.

[4] W. Jian-Jun, Y. Chang-Bo, and L. Qi-Han, "Stochastic Finite Element Method in Engineering [J]," Acta Mechanica Sinica, vol. 26, no. 2, pp. 297-303, 2009.

[5] M. Kamiński, "The Stochastic Perturbation Method for Computational Mechanics," The Stochastic Perturbation Method for Computational Mechanics, 2013. 


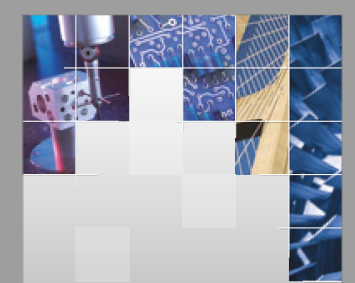

\section{Enfincering}
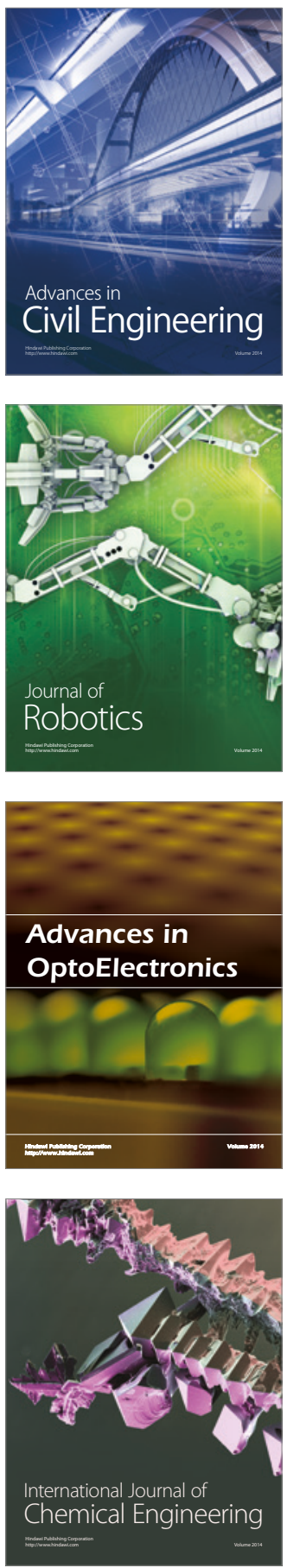

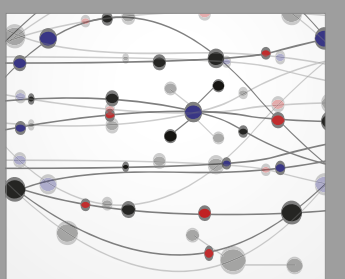

The Scientific World Journal

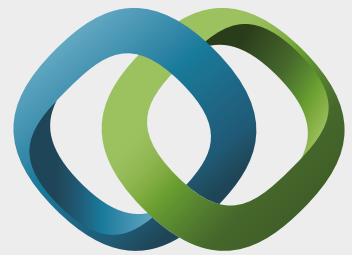

\section{Hindawi}

Submit your manuscripts at

https://www.hindawi.com
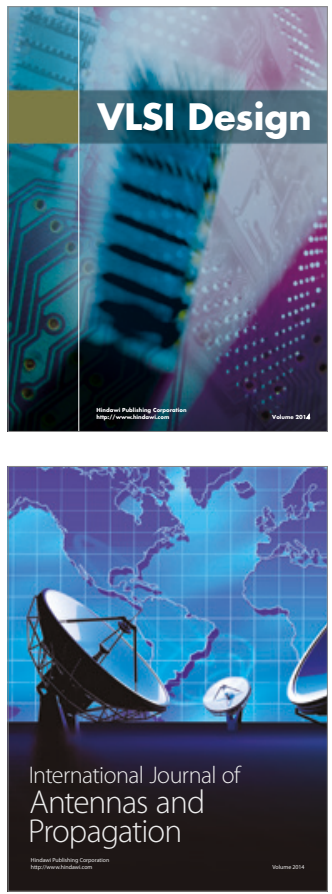

\section{Rotating}

Machinery
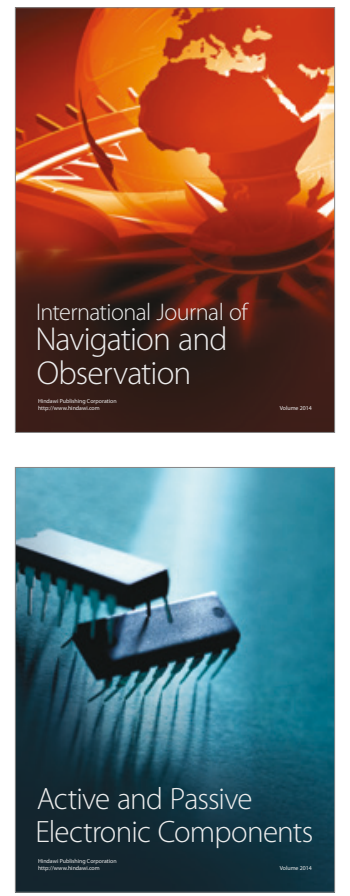
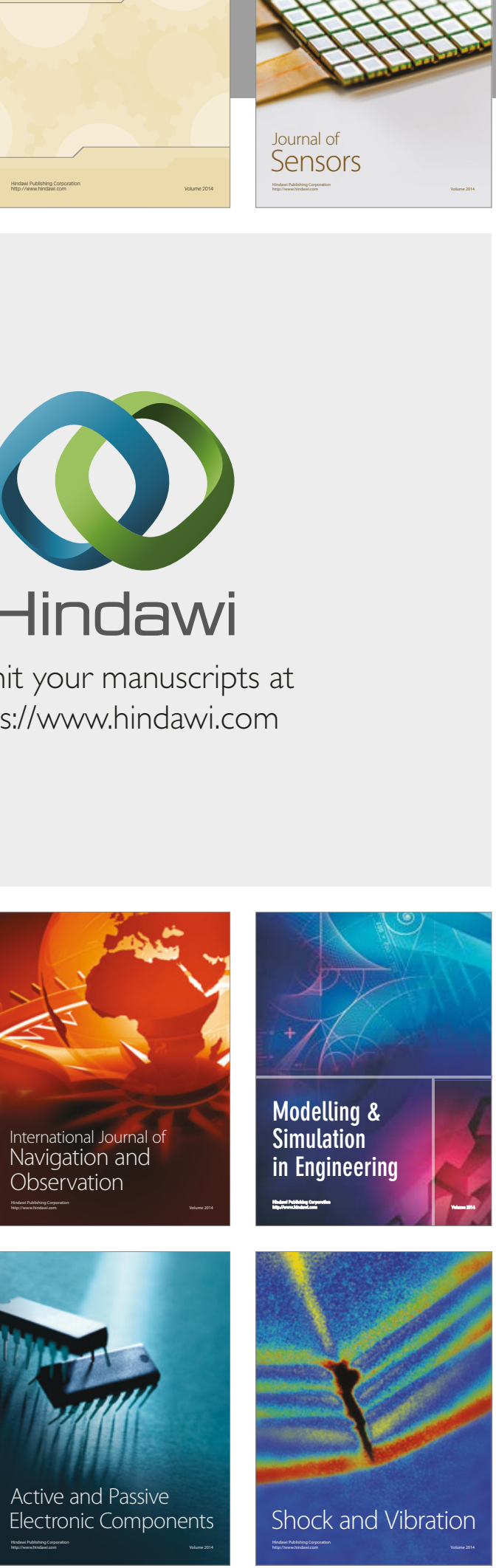
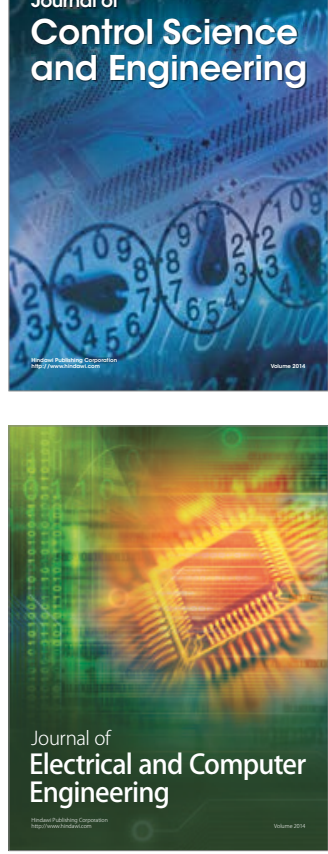

Distributed

Journal of

Control Science

and Engineering
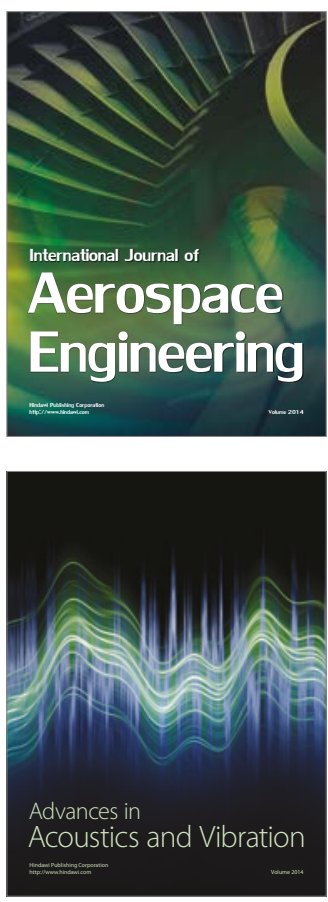

Sensor Networks 